\title{
Oral sucrose analgesia for preterm infant venepuncture
}

\section{A B Acharya, S Annamali, N A Taub, D Field}

\section{Clear benefit of sucrose analgesia for preterm neonates during venepuncture is shown}

lthough studies of oral sucrose
solution for procedure related
pain in neonates have been sub-
jected to a meta-analysis and a systema-
tic review, several problems have been
noted, and only one small trial focused
on the role of oral sucrose for preterm
venepuncture. ${ }^{1-3}$
We therefore performed a rando-
mised, double blinded, placebo con-
trolled, crossover trial of $25 \%$ sucrose
solution in healthy preterm infants to
assess its efficacy in reducing pain
responses during routine venepuncture.

\section{METHODS}

All well infants, below gestational age 37 weeks, admitted to the neonatal intensive care unit at Leicester Royal Infirmary, who needed routine blood sampling on at least two occasions were eligible for the study.

Exclusion criteria included unwell infants, need for oxygen or ventilation in the last seven days, intravenous feeding, five minute Apgar scores of 6 or less, neuromuscular dysfunction, grade 2 or more intraventricular haemorrhage, dysmorphic features, maternal opiate abuse, and need for analgesia or sedation within 48 hours of venepuncture.

Written informed consent was obtained from a parent. The local hospital ethics committee approved the study.

Infants received either $25 \%$ sucrose solution (S25) or water orally before two routine venepunctures. A hospital pharmacist used a table of random numbers to determine the order for each infant and kept records, which were made available only after complete analysis and scoring of data. One doctor (SA) performed all the venepunctures.

The infant's facial actions and cry were recorded throughout the venepuncture, using a video camera, by one of the authors (AA). A mirror placed on the opposite side of the crib or incubator allowed a reflected view of the face to be recorded if the infant turned its head away from the camera. Four minutes before the procedure, $2 \mathrm{ml}$ liquid was syringed over two minutes into the front of the infant's mouth. Venepuncture was performed as described in a previous study. ${ }^{4}$ The procedure was divided into three phases:

- pre-procedure, lasted for two minutes before hand holding;

- procedure phase from hand holding to needle removal;

- post-procedure phase lasted for three minutes from needle removal.

Heart rate and oxygen saturation were recorded at 30 second intervals throughout all three phases of the venepuncture. Verbal cues given at the point of hand holding, needle insertion, and needle removal were also recorded on the video camera.

A 30 second segment of tape before hand holding (phase 1), the segment between hand holding and needle insertion (phase 2), and a 30 second segment after needle insertion (phase 3) were scored separately using the neonatal facial coding system (NFCS) for each venepuncture by two blinded observers. ${ }^{5}$ The infant's behavioural state in period l segment was recorded using Prechtl's observational rating score. ${ }^{6}$

Cry was defined as audible vocalisation including crying, groaning, and whimpering after needle insertion. The infant's cry on videotape after needle insertion was timed by ear using a stopwatch (Lorus), to the nearest tenth of a second. Duration of first cry (from onset to end of first cry (cessation of crying for five seconds)) and total duration of crying (from onset of first cry to cessation of all crying) were recorded for all venepunctures. Difficulty of venepuncture was recorded as described elsewhere. ${ }^{4}$

Tabulation and analysis were carried out with Microsoft Excel and Minitab computer software packages using the paired $t$ test.

\section{RESULTS}

The data are from 39 of 44 infants recruited into the study who had two venepunctures. Five were discharged after only one venepuncture. Twenty two infants were male. Twenty five were white, 11 Asian, two afro-Caribbean, and one Arabic in origin. The mean (SD) gestational age at birth was 30.5 (2.3) weeks, and the mean (SD) postnatal age at inclusion in the study was 27.2 (24.4) days. Mean (SD) Apgar score at five minutes was $8.8(0.7)$. Twenty seven infants had required ventilation for surfactant deficient lung disease. Seven patients had been oxygen dependent for at least 28 days from birth. Mean (SD) interval between venepunctures was 6.6 (2.9) days. No infant required repeat venepuncture within 48 hours of the first.

Table 1 shows physiological and behavioural data for each phase of venepuncture. Significant effects were seen with S25 (table 2). Mean rise in heart rate as well as crying times and NFCS scores were significantly lower when the infants had received sucrose compared with water.

There was good inter-rater agreement for the NFCS scores given by the two authors for all the phases, as assessed by the Bland-Altman method. ${ }^{7}$ Behavioural state was not significantly different between the two liquids $(p=0.65)$. Difficulty and duration of venepuncture were not significantly different between the two liquids $(p=0.58)$. No infant

Table 1 Mean (SD) values for physiological and behavioural outcome measures

\begin{tabular}{|c|c|c|c|c|c|c|}
\hline \multirow[b]{2}{*}{ Variable } & \multicolumn{3}{|l|}{ Placebo } & \multicolumn{3}{|l|}{ S25 } \\
\hline & Phase 1 & Phase 2 & Phase 3 & Phase 1 & Phase 2 & Phase 3 \\
\hline HR (beats $/ \mathrm{min}$ ) & $156.9(11.7)$ & $168.6(12.8)$ & 3) $158.4(13.0)$ & $159.1(12.8)$ & $163.2(14.4)$ & $156.4(14.1)$ \\
\hline $\mathrm{SaO}_{2}(\%)$ & $96.8(1.9)$ & $95.5(2.7)$ & $97.1(1.8)$ & $97.2(2.1)$ & $96.5(2.2)$ & $96.5(2.4)$ \\
\hline NFCS (DF) & $0.26(0.59)$ & $1.85(2.31)$ & $5.92(2.45)$ & $0.13(0.41)$ & $0.64(1.25)$ & $3.41(2.69)$ \\
\hline NFCS (AA) & $0.18(0.60)$ & $1.46(2.06)$ & $5.85(2.25)$ & $0.03(0.16)$ & $0.54(1.14)$ & $3.08(2.67)$ \\
\hline $\mathrm{DFC}(\mathrm{s})$ & $52.3(56.2)$ & & & $18.6(24.4)$ & & \\
\hline $\operatorname{TDC}(\mathrm{s})$ & 72.5 (66.7) & & & $31.9(41.9)$ & & \\
\hline
\end{tabular}

For physiological criteria (HR, heart rate; $\mathrm{SaO}_{2}$, oxygen saturation) and crying times (DFC, duration of first cry; TDC, total duration of crying), phase 1 = pre-procedure phase, phase 2 = procedure phase, and phase 3 = post-procedure phase. For NFCS (neonatal facial action coding system), phase $1=30$ seconds before hand holding, phase 2 = hand holding to needle insertion, and phase $3=30$ seconds from needle insertion. AA and DF refer to individual authors. S25, 25\% sucrose solution; placebo, water 
Table 2 Treatment effect analysis of outcomes with water minus outcomes with S25

\begin{tabular}{|c|c|c|c|}
\hline Variable & $\begin{array}{l}\text { Estimated } \\
\text { treatment } \\
\text { effect }\end{array}$ & $95 \% \mathrm{Cl}$ & p Value \\
\hline $\begin{array}{l}\text { HR change from phase } 1 \text { (mean) to phase } 2 \\
\text { (mean) (beats } / \mathrm{min} \text { ) }\end{array}$ & 7.5 & 2.8 to 12.2 & 0.003 \\
\hline $\begin{array}{l}\text { HR change from phase } 1 \text { (mean) to phase } 3 \\
\text { (mean) (beats/min) }\end{array}$ & 4.16 & 0.29 to 8.03 & 0.036 \\
\hline $\begin{array}{l}\text { HR change from last } 2 \text { readings of phase } 1 \text { to } \\
\text { first } 2 \text { readings of phase } 2 \text { (beats } / \mathrm{min} \text { ) }\end{array}$ & 4.6 & 0.3 to 8.9 & 0.038 \\
\hline $\begin{array}{l}\mathrm{SaO}_{2} \text { change from phase } 1 \text { (mean) to phase } 2 \\
\text { (mean) (\%) }\end{array}$ & 0.61 & 0.27 to -1.5 & 0.17 \\
\hline Duration of first cry $(\mathrm{s})$ & 33.7 & 16.2 to 51.3 & $<0.001$ \\
\hline Total duration of crying (s) & 40.6 & 19.3 to 62.0 & $<0.001$ \\
\hline NFCS change from phase 1 to phase 3 & 2.39 & 1.25 to 3.52 & $<0.001$ \\
\hline NFCS change from phase 1 to phase 2 & 1.08 & 0.24 to 1.91 & 0.013 \\
\hline
\end{tabular}

For physiological criteria (HR, heart rate; $\mathrm{SaO}_{2}$, oxygen saturation) and crying times, phase $1=$ pre procedure phase, phase 2 = procedure phase, and phase $3=$ post-procedure phase. For NFCS (neonatal facial action coding system), phase $1=30$ seconds before hand holding, phase 2 = hand holding to needle insertion, and phase $3=30$ seconds from needle insertion. S25, 25\% sucrose solution.

developed necrotising enterocolitis, unlike a previous report. $^{8}$

\section{DISCUSSION}

This study shows that heart rate changes and behavioural responses to pain during venepuncture in healthy preterm neonates are significantly reduced by administration of $2 \mathrm{ml} \mathrm{25 \%}$ sucrose solution given orally two minutes before the procedure.

The only previous study of oral sucrose in preterm infants for relief of venepuncture related pain suggested beneficial effects. However, the study was relatively small $(\mathrm{n}=28)$, there were significant differences in gestational age and weight between the groups, and an observer measured crying duration during the venepuncture.

We believe the study presented here is more robust (with larger numbers, use of several different physiological and

\section{ACKNOWLEDGEMENTS}

nursing staff, Leicester Royal Infirmary neonatal intensive care unit, for their cooperation and help.

Arch Dis Child Fetal Neonatal Ed 2004:89:F17-F18

\section{Authors' affiliations}

A B Acharya, S Annamali, Department of Neonatal Medicine, Leicester Royal Infirmary, Leicester, UK

N A Taub, Department of Epidemiology and Public Health, University of Leicester D Field, Department of Child Health, University of Leicester

Correspondence to: Dr Acharya, Warwick Hospital, Lakin Road, Warwick CV34 6FA, UK; ashokachar@hotmail.com

\section{REFERENCES}

1 Stevens B, Ohlsson A. Sucrose for analgesia in newborn infants undergoing painful procedures (Cochrane review). Cochrane Library. Issue 3. Oxford: Update Software, 2001.

2 Stevens B, Taddio A, Ohlsson A, et al. The efficacy of sucrose for relieving procedural pain in neonates: a systematic review and meta-analysis. Acta Paediatr 1997;86:837-42.

3 Abad F, Diaz NM, Domenech E, et al. Oral sweet solution reduces pain related behaviour in preterm infants. Acta Paediatr 1996:85:854-8.

4 Acharya AB, Bustani PC, Phillips JD, et al. Randomised controlled trial of eutectic mixture of local anaesthetics cream for venipuncture in healthy preterm infants. Arch Dis Child Fetal Neonatal Ed 1998;78:F138-42.

5 Craig KD, Grunau RVE. Neonatal pain perception and behavioural measurement. In: Anand KJS, McGrath PJ, eds. Pain in neonates. Amsterdam: Elsevier Science Publishers BV, 1993:66-99.

6 Prechtl HFR. The behavioural states of the newborn infant. A review. Brain Res 1074;76:185-212

7 Bland JM, Altman DG. Statistical methods for assessing agreement between two methods of clinical measurement. Lancet 1986;i:307-10.

8 Wills DM, Chabot J, Radde IC, et al. Unsuspected hyperosmolality of oral solutions contributing to necrotising enterocolitis. Pediatrics 1977:60:535-8

We thank Chris Cutts, pharmacist, for his help with the study. We also thank the
9 Johnston CC, Stevens BJ. Experience in a neonatal intensive care unit affects pain response. Pediatrics 1996:98:925-30. 